\title{
CORRIGENDUM
}

\section{Cross talk between apoptosis and autophagy by caspase-mediated cleavage of Beclin 1}

\author{
M Djavaheri-Mergny, MC Maiuri and G Kroemer
}

Oncogene (2010) 29, 6508; doi:10.1038/onc.2010.514

Correction to: Oncogene (2010) 29, 1717-1719; doi:10.1038/onc.2009.519; published online 25 January 2010
After the publication of the article, the authors noticed an error in Figure 1. The authors would like to apologize for this mistake. The correct figure is reproduced below.

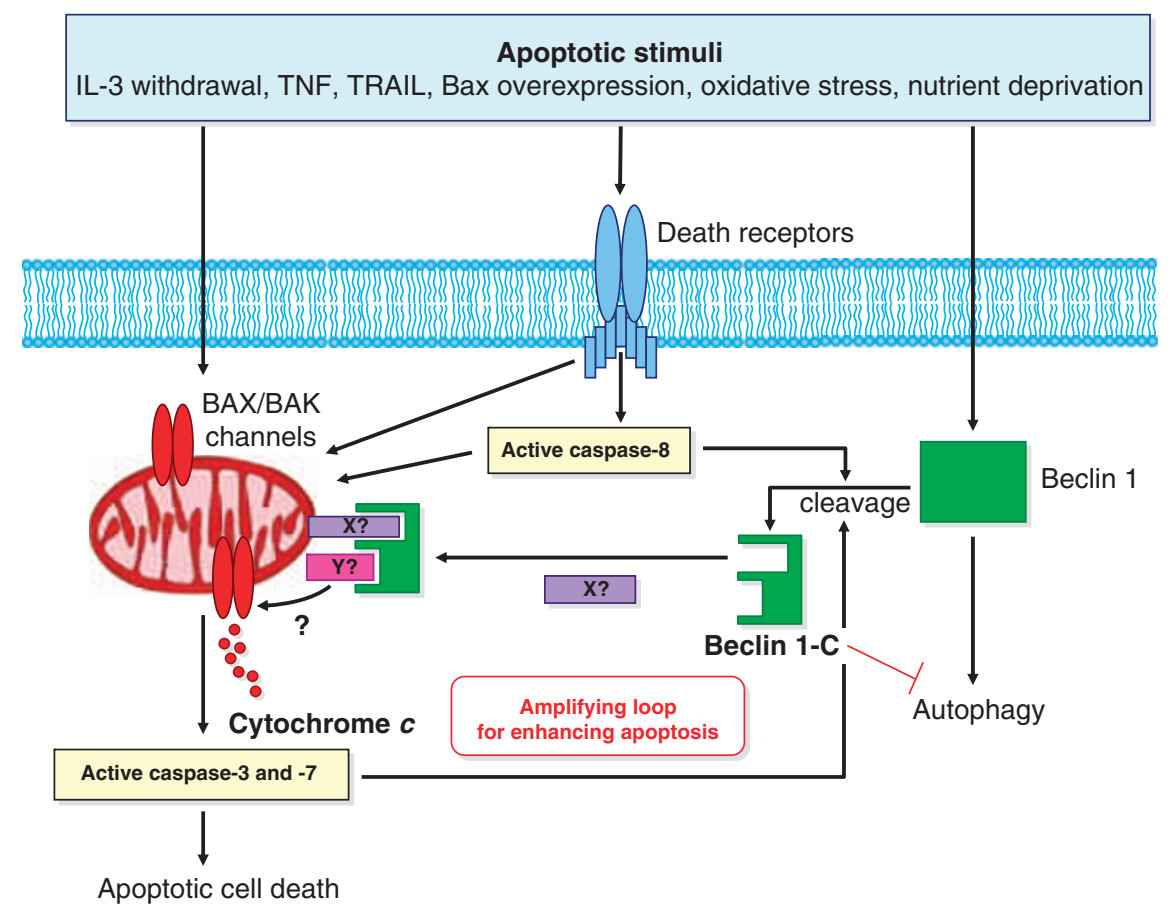

Figure 1 